\title{
O FIDEÍsmo Místico DE DEMEA E SUA CRÍTICA AO ANTROPOMORFISMO NOS DIÁLOGOS DE HUME
}

\author{
Demea's Mystic Fideism and his Critique of Anthropomorphism \\ in Hume's Dialogues
}

Marília Côrtes de Ferraz *

Resumo: Hume, nos Diálogos sobre a religião natural, faz com que o personagem Demea defenda algumas teses que, a meu ver, podem ser formuladas do seguinte modo: i) a assimilação dos tradicionais atributos divinos depende de argumentos místico-religiosos, pois nossa razão, embora seja potente para provar a existência de Deus, não tem poderes para nos dizer qual a sua natureza; ii) o antropomorfismo implicado na tese de Cleanthes é inaceitável; e iii) a existência de Deus pode e deve ser demonstrada por um argumento formal ou prova a priori. Pretendo, neste artigo, examinar conjuntamente as duas primeiras teses, uma vez que as entendo como teses solidárias, isto é, uma implica a outra. Defendo que o fideísmo místico (ou misticismo religioso) de Demea está circunscrito à sua concepção religiosa cristã e que seu compromisso mais forte em sua crítica ao argumento do desígnio é com a teologia racional subjacente à prova da existência de Deus. Para tanto, faço um exame dos argumentos que Demea oferece contra o antropomorfismo implicado no argumento do desígnio e suas relações com aquilo que chamei de fideísmo místico.

Palavras-chave: Religião Natural. Existência de Deus. Natureza Divina. Fideísmo Místico. Antropomorfismo.

Abstract: In the Dialogues on natural religion, Hume makes his character Demea defend some theses that, in my view, can be formulated as follows: i) the assimilation of the traditional divine attributes depends on mystical religious

* Doutora em Filosofia pela Universidade de São Paulo (USP); Pós-doutoranda em Filosofia pela Universidade Federal de Santa Catarina (UFSC) no PNPD/CAPES.Artigo recebido em 23/04/2018 e aprovado para publicação em 11/02/2019. 
arguments, because, although our reason can prove the existence of God, it cannot tell us anything about its nature; ii) the anthropomorphism involved in Cleanthes' thesis is unacceptable; and iii) the existence of God can and must be demonstrated by a formal argument or an a priori proof. In this paper, I intend to analyze the first two theses jointly, since I understand that one implies the other. I shall argue that Demea's mystical fideism (or religious mysticism) is circumscribed to his Christian religious conception and that his strongest commitment to the critique of the design argument concerns the rational theology underlying the proof of God's existence. To do so, I examine the arguments that Demea offers against the anthropomorphism involved in the design argument and its relationship to what I have called mystical fideism.

Keywords: Natural Religion. Existence of God. Divine Nature. Fideism. Anthropomorphism.

\section{Introdução}

$\mathrm{H}$ ume, nos Diálogos sobre a religião natural ${ }^{1}$, faz com que o personagem Demea defenda algumas teses que, a meu ver, podem ser formuladas do seguinte modo: i) a assimilação dos tradicionais atributos divinos depende de argumentos místico-religiosos, pois nossa razão, embora seja potente para provar a existência de Deus, não tem poderes para nos dizer qual a sua natureza; ii) o antropomorfismo implicado na tese de Cleanthes é inaceitável; e iii) a existência de Deus pode e deve ser demonstrada por um argumento formal ou prova a priori. Neste artigo, limito-me a tratar, conjuntamente, das duas primeiras teses, uma vez que as entendo como teses solidárias, quer dizer, uma implica a outra. Defendo que o fideísmo místico ou misticismo religioso de Demea está circunscrito à sua concepção religiosa cristã e que seu compromisso mais forte em sua crítica ao argumento do desígnio é com a teologia racional, subjacente à prova da existência de Deus. Para tanto, faço um exame dos argumentos que Demea oferece contra o antropomorfismo implicado no argumento do desígnio e suas relações com aquilo que chamei de fideísmo místico.

Nos Diálogos, além do narrador Pamphilus, dois dos três participantes da discussão, Demea e Philo, afirmam que a existência de Deus é uma verdade certa e self-evident ${ }^{2}$ e que, por isso, não está aberta à disputa por pessoas razoáveis. Há, no início da parte 2 , uma declaração incisiva de Demea a respeito do tema principal da obra. Ele afirma que a existência

\footnotetext{
${ }^{1}$ HUME, David. Dialogues Concerning Natural Religion and (NHR) The Natural History of Religion. Edited by J. C. A. Gaskin. Oxford: University Press, 1993,Ao referir-me às obras clássicas de Hume, indicarei apenas o autor e a obra, seguida do número do livro, parte ou seção; parágrafo (quando houver); e página citada.

${ }^{2}$ Cleanthes também afirma a existência de Deus, mas não diz que ela é self-evident.
} 
de Deus não está em questão, ou não deve, ao menos entre eles, estar em questão.

Estou convencido de que ninguém ou, pelo menos, ninguém dotado de bom senso, jamais alimentou sérias dúvidas com relação a uma verdade tão certa e self-evident. A questão não diz respeito à existência, mas à natureza de Deus. ${ }^{3}$ E esta, eu afirmo, devido à fragilidade do entendimento humano, é-nos completamente incompreensível e desconhecida. ${ }^{4}$

Com base nessa afirmação poderíamos ser levados a concluir que Demea assume uma posição segundo a qual a fé seria suficiente para a aceitação dos atributos tradicionais referidos a Deus, os quais não passariam de palavras de veneração dirigidas à Divindade. ${ }^{5}$ Porém, uma vez que Demea diz que ninguém dotado de razão e bom senso duvidaria da existência de Deus, ele sugere dispor de argumentos em favor de sua existência. Nesse caso, cabe perguntar: apenas a razão seria suficiente para nos convencer de que Deus existe? Ora, pode-se argumentar que, se assim o fosse, nem seria necessário ter fé, o que obviamente não implica, ainda que a razão fosse suficiente para provar a existência de Deus, a exclusão da fé. Coerente com essa sugestão, Demea apresenta uma prova para a existência de Deus nos termos da teologia racional ou, dito de outro modo, com base em argumentos racionais. Entretanto, a oferta de um argumento em favor da existência de Deus será feita por Demea somente na parte 9 dos Diálogos - parte que tem sido amplamente considerada uma refutação conclusiva do argumento cosmológico para a existência de Deus, e que não será aqui desenvolvida. Na sequência de seu discurso, o que vemos é a sua perseverança na ideia de que a fragilidade do entendimento humano jamais conseguirá conceber a essência da mente suprema, seus atributos, seu modo de existência e a natureza de sua duração. Para Demea, há uma espessa névoa encobrindo as infinitas perfeições de Deus. Por isso, a nós cabe adorá-las em silêncio, pois "tentar penetrar nessa obscuridade sagrada", diz Demea, "constitui profanação", e "a temeridade de perscrutar seus decretos e atributos, sua natureza e essência, aproxima-se da atitude ímpia de negar sua existência" ${ }^{6}$

\footnotetext{
${ }^{3}$ Hume, na voz de Demea, ecoa aqui a observação do estoico Balbus em A natureza dos deuses, de Cícero: "é a natureza de Deus que está em questão, e não a sua existência" (CÍCERO, Marco Túlio (2004). Da Natureza dos Deuses. Tradução de Pedro Braga Falcão. Lisboa: Nova Veja, 2004, p. 128.

${ }^{4}$ HUME, David. Dialogues Concerning Natural Religion and (NHR) The Natural History of Religion. Edited by J. C. A. Gaskin. Oxford: University Press, 1993, D 2 § 1, p. 43.

${ }^{5} \mathrm{O}$ que Philo textualmente (mas talvez não sinceramente) defenderá, em concordância com Demea. Philo diz: “É certo que quando esses assuntos são tratados por pessoas razoáveis, o que está em questão jamais pode ser a existência, mas apenas a natureza da Divindade. Como você [Demea] bem observou, a primeira verdade é inquestionável e self-evident" (HUME, David. Dialogues Concerning Natural Religion, D 2 § 3, p. 44). Digo "talvez não sinceramente" porque se discute amplamente e é razoável sustentar que a concordância de Philo é apenas aparente e que ele, no fundo, não esposa tal tese.

${ }^{6}$ HUME, David. Dialogues Concerning Natural Religion, D 2 § 1, p. 43.
} 


\section{Fideismo mistico versus antropomorfismo}

Após o pronunciamento de Cleanthes favorável ao argumento do desígnio, ${ }^{7}$ ainda na parte 2, Demea professa que a conclusão de Cleanthes sobre a semelhança da Divindade com o ser humano é tão inaceitável quanto os meios que ele usa para estabelecê-la. E a conclusão seria inaceitável precisamente porque se fundamenta em argumentos antropomórficos. Mas qual é exatamente o problema com o antropomorfismo? O que haveria de tão aviltante em formarmos concepções antropomórficas acerca do ser divino?

Antes de oferecer respostas a essas questões, convém salientar que embora toda a argumentação de Demea vá contra a concepção antropomórfica, pode-se argumentar, como o faz Holley em The Role of Anthropomorphism in Hume's Critique of Theism (2002), que o antropomorfismo comporta graus de aceitabilidade e razoabilidade. Pois uma coisa é atribuir traços humanos depreciadores da divindade, como sentimentos de vingança, inveja, vícios e outras fraquezas demasiado humanas. Outra coisa é atribuir características humanas enaltecedoras, como sabedoria, inteligência, perfeição, justiça e benevolência. Ainda que Demea venha a argumentar que mesmo os atributos enaltecedores sejam aviltantes em virtude de serem atribuídos a Deus a partir das noções que temos dessas qualidades nos seres humanos, a recusa total do antropomorfismo nos conduz a uma espécie de paradoxo, uma vez que sem o modelo da representação humana não poderíamos nem ter a ideia de Deus. Noções de inteligência, poder, sabedoria, benevolência, propósito, perfeição, virtudes e vícios, nascem todas da representação que temos de nós mesmos e dos outros seres humanos. Quer dizer, sem o modelo da representação humana restaria aos teístas muito pouco a dizer sobre o significado religioso de Deus. ${ }^{8}$

Cumpre observar, ainda, a distinção entre o teísmo racional (ortodoxo tradicional) sustentado por Demea (ao menos em relação à existência de Deus, já que em relação à natureza divina ele adere ao que chamei de fideísmo místico), e o teísmo experimental (menos ortodoxo e mais moderno) sus-

\footnotetext{
${ }^{7}$ Argumento segundo o qual, a partir da experiência e observação da ordem do universo e dos produtos do engenho humano, podemos inferir que o mundo foi projetado ou planejado por um ser (arquiteto-designer) extremamente inteligente, e que esse ser é Deus. Portanto, conclui-se que Deus existe e se assemelha aos seres humanos. Nas palavras do próprio Cleanthes: "é por meio deste argumento a posteriori, e apenas por meio dele, que chegamos a provar, a um só tempo, a existência de uma Divindade e sua similaridade com a mente e inteligência humanas" (HUME, David. Dialogues Concerning Natural Religion, D 2: § 5, p. 45). ${ }^{8}$ HOLLEY, David M. (2002). The Role of Anthropomorphism in Hume's Critique of Theism. In: International Journal for Philosophy of Religion, vol. 51, $\mathrm{n}^{\circ} 2$ (April, 2002), p. 83-84.

9 Embora Cleanthes defenda um "teísmo experimental" e, nesse sentido, se mostre mais "moderno" do que Demea, ele não deixa de ser um cristão ortodoxo, tomando o termo "ortodoxo" em sentido lato, obviamente, ou seja, apenas como tradicional. Penso que Cleanthes
} 
tentado por Cleanthes. ${ }^{9} \mathrm{O}$ primeiro recusa o antropomorfismo e o segundo o defende, não obstante, os dois sejam teístas. Nesse sentido, a obstinada defesa do antropomorfismo por parte de Cleanthes, como representante de um tipo de teísmo, pode significar "um tiro em seu próprio pé", pois ao defender uma semelhança excessiva entre os atributos humanos e os atributos divinos,,$^{10}$ ele acabará tendo que renunciar a atributos cruciais pertencentes à divindade, como por exemplo, segundo a crítica de Philo, "qualquer pretensão de infinitude em qualquer dos atributos da Divindade". ${ }^{11}$ E de fato, na parte 11 dos Diálogos a discussão leva Cleanthes a renunciar a infinitude dos atributos divinos. ${ }^{12}$ Creio que é em virtude disso que Demea acusa Cleanthes de que ele, ao defender o antropomorfismo, não seria um "autêntico teísta" ${ }^{13}$ Nessa passagem, Demea apoia a tese da "perfeita imutabilidade e simplicidade divinas" na autoridade de todos os "autênticos teístas" (sem nomeá-los propriamente). A passagem é curiosa, pois Demea parece falar por Hume ao responder à pergunta que ele mesmo coloca: “Que é a alma do homem? Um composto de várias faculdades, paixões, sentimentos e ideias; unidas, é verdade, em um só ego ou pessoa, mas ainda assim distintas umas das outras". ${ }^{14}$

Frederick Ferré observa em In Praise of Anthropomorphism (1984) que o principal motivo para rejeitar o uso da linguagem antropomórfica em relação a Deus, subjaz profundamente na tradição espiritual que insiste em defender o valor supremo do ser divino contra a sua profanação por meio da atribuição de características humanas. ${ }^{15}$ Tal defesa vem ao encontro da crítica de Demea ao antropomorfismo, pois, sendo ele um representante dessa tradição espiritual, não se apresenta nada surpreendente que ele considere a analogia inicial operada por Cleanthes muita pretensão e impiedade. Mas Ferré empreende uma defesa da linguagem antropomórfica em relação ao sagrado. Em seu artigo ele examina o antagonismo localizado no discurso antropomórfico sobre Deus, oferecendo razões para antes louvar do que abandonar tal discurso. ${ }^{16}$

é ortodoxo porque ele mantém que Deus possui a maioria dos atributos divinos tradicionais. Já Demea, como adepto do tradicional teísmo racional, é ainda mais ortodoxo, na medida em que adota a perspectiva "demonstrativa a priori".

${ }^{10}$ Cf. HUME, David. Dialogues Concerning Natural Religion, D $5 \S 4$, p. 68.

${ }^{11}$ Ibid. D $5 \S 5$, p. 68.

${ }^{12}$ Ibid. D $11 \S 1$, p. 105.

${ }^{13}$ Ibid. D 4 § 2, p. 61. Seguindo o raciocínio de Demea, Cleanthes, ao abdicar de atributos essenciais da divindade, seria, então, um teísta inautêntico.

${ }^{14} \mathrm{Ibid}$. D 4 § 2, p. 61. Mutatis mutandis, tal passagem parece fazer eco à definição humeana da identidade pessoal (mente ou eu), no Tratado, como um feixe de diversas percepções (HUME, David. A Treatise of Human Nature. Ed. D. F. Norton \& M. J. Norton. Oxford: University Press, 2002, 1.4.6 § 1, p. 164 e ssg).

${ }^{15}$ FERRÉ, Frederick e FERRÉ R. In Praise of Anthropomorphism. In: International Journal for Philosophy of Religion, Vol 16, no 3,1984, p. 203-204.

${ }^{16}$ Ibid. p. 203, 206-208. 
Contrariamente a essa ideia, Demea alega que "ao representarmos a divindade como sendo tão inteligível e compreensível, e tão similar à mente humana, tornamo-nos culpados da mais grosseira e estreita parcialidade e fazemos de nós mesmos o modelo de todo o Universo".${ }^{17}$ Para Demea, em virtude de sermos "criaturas finitas, débeis e cegas, devemos nos humilhar diante de sua augusta presença e, conscientes de nossas falhas, adorar em silêncio suas infinitas perfeições, que os olhos não podem ver, nem os ouvidos escutar, e que ao coração do homem não é dado conceber" ${ }^{18}$

Pitson, por sua vez, em The Miseries of Life: Hume and the Problem of Evil (2008), destaca que "o objetivo de atribuir perfeições como sabedoria e conhecimento ao ser divino é essencialmente o de capacitar-nos, por meio disso, a expressar nossa adoração a ele" ${ }^{19} \mathrm{E}$ isso tanto Demea quanto Philo defendem. Uma das estratégias de Demea contra o antropomorfismo é argumentar em favor de que todos os materiais do nosso pensamento são provenientes somente de duas fontes: sentidos internos e sentidos externos, os quais compõem toda a bagagem do entendimento humano. ${ }^{20}$ Ora, uma vez que as ideias derivadas dos sentidos são, segundo Demea, reconhecidamente falsas e enganosas, não podem ter lugar em uma inteligência suprema. Sendo assim, os materiais do nosso pensamento não podem se assemelhar em nenhum aspecto a uma inteligência tão distinta e distante como a divina. Na visão de Demea, "as debilidades de nossa natureza não nos permitem apreender quaisquer ideias que tenham a mínima correspondência com a inefável sublimidade dos atributos divinos" ${ }^{21}$ Quer dizer, a grandiosidade divina não é apenas inexplicável, por ser obscura e incompreensível, ela é mais do que isso, na verdade ela é mesmo indizível ou inexprimível por palavras. Daí a afirmação segundo a qual "devemos adorar em silêncio suas infinitas perfeições". ${ }^{22}$ Sendo nossos pensamentos fugazes, vacilantes e incertos, não podemos dizer que Deus raciocina como nós. Nossos padrões de verdadeiro ou falso não são aplicáveis aos juízos que fazemos sobre seus atributos. Por isso, não podemos descrever Deus com as mesmas palavras que usamos para falar de criaturas tão limitadas e corruptas como os seres humanos. ${ }^{23}$ Valendo-se de Malebranche, Demea

\footnotetext{
${ }^{17}$ HUME, David. Dialogues Concerning Natural Religion, D $3 \S 12$, p. 58.

${ }^{18}$ Ibid. D 2 § 1, p. 43.

${ }^{19}$ PITSON, Tony. The Miseries of Life: Hume and the Problem of Evil. In: Hume Studies. Vol. 34, Number 1, April, 2008, p. 90.

${ }^{20}$ HUME, David. Dialogues Concerning Natural Religion, D $3 \S 13$, p. 58). Esta tese é textualmente defendida por Hume na seção $2 \S 5$, p. 25 do seu An Enquiry concerning Human Understanding. Edited by Tom L. Beauchamp. Oxford: University Press, 1999. Nesse caso, talvez se possa dizer que essa é uma das poucas vezes em que Demea fala por Hume.

${ }^{21}$ HUME, David. Dialogues Concerning Natural Religion, D $3 \S 13$, p. 59.

${ }^{22}$ Ibid. D $2 \S 1$, p. 43.

${ }^{23} \mathrm{Um}$ dos motivos disso, ao que parece, é que há, segundo Philo, uma dificuldade instransponível dos seres humanos de esquadrinhar relações infinitas (HUME, David. Dialogues Concerning Natural Religion, D $5 \S 6$, p. 69). Em Berkeley podemos encontrar essa mesma concepção. No Tratado Sobre os Princípios do Conhecimento Humano ele diz: "quando o espírito
} 
diz: "seu verdadeiro nome é Aquele que é, ou, em outras palavras, o Ser sem qualquer restrição, Todo o Ser, o Ser infinito e universal". ${ }^{24}$ Agostinho e Tomás de Aquino também sustentam que o nome mais apropriado a Deus é aquele que foi dado por Moisés pela voz que saiu da sarça ardente: Eu Sou o que Sou, o que claramente identifica a essência de Deus com a sua existência. ${ }^{25}$ Percebe-se, assim, que Demea alinha-se àqueles que ele mesmo chama de "autênticos teístas."

Na linha dessas reflexões, Pitson destaca a sugestão de Philo de que a linguagem empregada na caracterização da divindade tem antes uma função expressiva do que propriamente descritiva. Quer dizer, “a atribuição de perfeição a Deus não reflete o conteúdo das ideias correspondentes, mas sim capacita-nos a dar expressão à atitude de devoção que a contemplação do divino tende a evocar". ${ }^{26}$ No entanto, Pitson observa que numa carta a William Mure of Caldwell, Hume foi cuidadoso em distinguir o uso da linguagem religiosa da prece petitória, pois ainda que aceitemos que essa última seja "uma espécie de 'figura retórica' pela qual nossos anseios e desejos se tornam mais ardentes e apaixonados, somos culpados de blasfêmia na medida em que imaginamos que tais preces possam influenciar diretamente a divindade ${ }^{\prime 2}{ }^{27}$ Holley também se alinha a essa interpretação de Pitson ao afirmar que, para Philo e Demea, "a linguagem sobre Deus serve a uma função puramente expressiva". ${ }^{28}$

Contudo, contrariamente a Philo e Demea, desde o início Cleanthes considera crucial dizer alguma coisa sobre a natureza de Deus - algo que dê ao menos alguma ideia de sua realidade. Ele acredita ser absolutamente essencial dizer, por exemplo, que Deus possui mente ou inteligência, e que o único modo de defender isso seria declarar que a mente de Deus tem características semelhantes às da mente humana. Para Cleanthes, não há nenhum fundamento em demonstrar respeito a algo que é ao mesmo tempo incompreensível e misterioso. ${ }^{29}$ No entanto, pode-se argumentar, e é isso que Demea faz, que é justamente pelo fato de Deus ser incompreensível e misterioso que devemos, em silêncio, respeitá-lo e adorá-lo.

Na visão de Pike, Cleanthes se opõe à ideia de que a linguagem religiosa tem função puramente expressiva ao reivindicar que os termos usados

\footnotetext{
finito do homem quer ocupar-se do que participa da infinidade, não admira vê-lo cair em absurdos e contradições de que não consegue desenredar-se, por ser da natureza do infinito a sua incompreensibilidade pelo finito" (BERKELEY, George. Três diálogos entre Hilas e Filonous em oposição aos céticos e ateus, 1973, p. 11).

${ }^{24}$ HUME, David. Dialogues Concerning Natural Religion, D 2 § 2, p. 44.

${ }^{25}$ Essa passagem encontra-se no Velho Testamento da Bíblia Sagrada, Livro do Êxodo, versículo

3.14 Acesso em https://www.bibliaonline.com.br/acf/ex/3

${ }^{26}$ PITSON, ob. cit. p.107, n.6.

27 Ibid. p. 113-114, n.48.

${ }^{28}$ HOLLEY, ob. cit., p. 89.

${ }^{29}$ Ibid. p. 90.
} 
na descrição do criador do universo carregam o significado que eles têm na linguagem ordinária, e que, assim entendidos, não são termos usados meramente para expressar honra e respeito, mas termos completamente aplicáveis a real natureza de Deus, ${ }^{30}$ tal como evidencia a seguinte pergunta de Cleanthes a Demea: "se nossas ideias, até onde alcançam, não são justas, adequadas e correspondentes à sua real natureza, então não sei o que há neste assunto que valeria a pena insistir. É um nome, sem qualquer significado, de tão grande importância" ${ }^{31}$ ?

Pois bem, se Demea argumenta em favor de que todos os materiais do pensamento são provenientes somente dos sentidos internos e sentidos externos, e que estes compõem toda a bagagem do entendimento humano, ${ }^{32}$ como pensar ou falar sobre Deus sem recorrer ao antropomorfismo?

Holley, na esteira de Ferré, argumenta que tentar transcender a origem antropomórfica de nossas ideias sobre Deus pode implicar a remoção do que é necessário para dar significado coerente àquilo que pensamos sobre Deus. ${ }^{33}$ Ele defende que sem um certo grau de antropomorfismo as práticas religiosas teístas entrariam em colapso. De fato, o próprio Hume parece aceitar "um certo grau de antropomorfismo" quando, na seção 2 da Investigação sobre o entendimento humano [EHU], diz que "a ideia de Deus, no sentido de um Ser infinitamente inteligente, sábio e bondoso, surge da reflexão sobre as operações de nossa própria mente e do aumento ilimitado dessas qualidades de bondade e sabedoria". ${ }^{34} \mathrm{E}$ ainda, na seção 7 da mesma obra, quando declara que "não temos nenhuma ideia de um Ser Supremo, exceto pelo que aprendemos a partir da reflexão sobre nossas próprias faculdades" ${ }^{35}$

Dessa perspectiva, vale notar que o problema diz respeito à origem e forma de se chegar à ideia de Deus. A pergunta subjacente a EHU e que se estende aos Diálogos é: que ideia formamos de sua natureza? Mas nos Diálogos o ponto não se resume a isso, tampouco se apresenta como o mais relevante. Os Diálogos versam, principalmente, sobre a legitimidade e plausibilidade da inferência que fazemos sobre a existência e a natureza de Deus a partir do argumento do desígnio, isto é, a partir da observação da ordem do mundo e não da observação das operações de nossa própria mente. Sob este aspecto, o problema não incide propriamente sobre a origem da ideia de Deus, ou como a formamos em nossa mente, mas sim e

\footnotetext{
${ }^{30}$ PIKE, Nelson. Hume on the argument from design, 1970. p. 139-141.

${ }^{31}$ HUME, David. Dialogues Concerning Natural Religion, D 4 § 1, p. 60.

${ }^{32}$ Ibid. D $3 \S 13$, p. 58.

${ }^{33}$ HOLLEY, ob. cit. p. 86.

${ }^{34}$ HUME, David. An Enquiry concerning Human Understanding. Edited by Tom L. Beauchamp.

Oxford: University Press, 1999, $2 \S 6$, p. 98.

${ }^{35}$ Ibid. $7 \S 25$, p. 143.
} 
diretamente sobre a afirmação da existência de um Deus com tais e tais atributos. Quer dizer: uma coisa é ter a ideia de Deus e de sua natureza a partir da reflexão sobre as operações de nossa própria mente - tema tratado na seção 7 de EHU -, e crer ou não crer nele em virtude de certos fatores psicológicos relacionados à nossa constituição natural que, por sua vez, levam-nos a formar essa crença - tema da História Natural da Religião -; outra coisa é afirmar a existência de Deus e conferir-lhe atributos a partir da hipótese do desígnio - tema dos Diálogos. Porém, a despeito dessas perspectivas distintas, é preciso manter em mente que qualquer crença ou prática religiosa teísta tem, inevitavelmente, de recorrer à representação antropomórfica, pelo simples fato de que só podemos pensar em Deus a partir dos materiais fornecidos pelo nosso próprio pensamento.

Pode-se dizer, pois, que o ponto central da crítica de Demea ao antropomorfismo é que, da perspectiva antropomórfica, os atributos divinos seriam todos concebidos em termos de diferença de grau e não de natureza, ou, em outras palavras, os atributos divinos teriam a mesma natureza que os nossos, diferenciando-se apenas em magnitude. Ora, para um teísta ortodoxo, reminiscente do racionalismo escolástico, essa é uma "visão parcial e ímpia" que, nas palavras de Philo, tradicionalmente, "nenhum teísta consistente pode tolerar". ${ }^{36}$ Entretanto, na História Natural da Religião, Hume mostra que o antropomorfismo surge de uma inclinação natural (ou uma tendência universal) dos seres humanos
para conceber todos os seres como eles próprios, e para transferir a todos os objetos aquelas qualidades com as quais eles estão mais familiarizados, e das quais estão intimamente conscientes. Encontramos faces humanas na lua, exércitos nas nuvens, e, por uma propensão natural, se não for corrigida pela experiência e pela reflexão, atribuímos malícia ou boa-vontade a tudo que nos faz mal ou nos agrada. ${ }^{37}$

Hume diz que isso é uma fraqueza natural: "a imaginação ativa dos homens incomodada pelas concepções abstratas dos objetos, [...] começa a torná-los mais precisos e a revesti-los com formas mais adequadas à sua compreensão natural". ${ }^{38}$ Curiosamente, nessa obra, Hume defende textualmente a hipótese do desígnio ${ }^{39}$ - o que implica a aceitação do antropomorfismo. Ora, se o antropomorfismo surge de uma reflexão sobre nossa própria mente, bem como de uma tendência natural em conceber todos os seres segundo nossa própria imagem, isso, num certo sentido, colide

\footnotetext{
${ }^{36}$ HUME, David. Dialogues Concerning Natural Religion, D 2 § 15, p. 48.

${ }^{37}$ HUME, David. The Natural History of Religion. Edited by J. C. A. Gaskin. Oxford: University Press, 1993, 3, p. 141.

${ }^{38}$ Ibid. 8, p. 159.

${ }^{39}$ Ainda que se possa argumentar que ele faz isso apenas retoricamente se levarmos em conta a sua crítica à religião em geral e o cabedal de argumentos que Philo, como seu principal porta-voz, apresenta contra o argumento do desígnio.
} 
com a crítica humeana ao antropomorfismo nos Diálogos. Pois ao mesmo tempo em que ali Hume rejeita o antropomorfismo, aliás, não só nos $D i$ álogos, mas também na seção 11 de EHU (§ 27), ele sustenta teorias que o admitem como praticamente inevitável. Quer dizer, Hume constrói teorias que, ao menos à primeira vista, apresentam-se contraditórias. Qual seria então o propósito da crítica de Hume ao antropomorfismo nos Diálogos, se, conforme procurei mostrar, o antropomorfismo é inevitável e Hume não se mostra desavisado disso?

Holley sugere que uma estratégia central do ataque de Hume ao teísmo é explorar a tensão interna que existe, dentro da tradição teísta, entre o desejo de dizer algo de substancial sobre a natureza divina e o interesse de purificar o conceito de Deus do inaceitável antropomorfismo. Na interpretação de Holley, Hume exibe uma certa ironia ao colocar a ortodoxia de Demea próxima ao ceticismo filosófico de Philo. Demea está disposto a afirmar piamente a infinita perfeição de "alguma coisa que ele não sabe o que é". ${ }^{40}$ Philo concorda com a afirmação de Demea sobre a natureza self-evident da verdade de que Deus existe, e sua cética negação do conhecimento do que Deus é corre paralelamente ao agnosticismo pio de Demea. O Deus cuja existência Hume aparentemente se mostra preparado para afirmar é aquele que está desprovido da bagagem antropomórfica necessária para dar suporte às formas reconhecíveis de práticas religiosas. ${ }^{41}$ Ao concordar com Demea que "o que está em questão jamais pode ser a existência, mas apenas a natureza de Deus", Philo admite como uma "inquestionável primeira verdade" que "nada existe sem uma causa, e a causa original deste universo (qualquer que ela seja) nós a denominamos Deus, e lhe atribuímos devotadamente todas as espécies de perfeições". ${ }^{42}$ Mas vale lembrar que essa "inquestionável primeira verdade" foi, ainda que não de forma direta, questionada por Hume no Tratado sobre a Natureza Humana - seção intitulada "Por que uma causa é sempre necessária?" - e representa um ponto central de sua epistemologia. ${ }^{43}$ Nesse caso, uma identificação de Hume, bastante aceita entre seus comentadores, com o personagem Philo, para ser consistente, exige que interpretemos essa afirmação como sendo apenas uma estratégia retórica e/ou que assumamos que nem tudo o que Philo diz está de acordo com o que Hume pensa. A meu ver, as duas interpretações são procedentes. Na parte 9 dos Diálogos, Philo e Cleanthes se aliam contra a prova de Demea que afirma tanto em sua primeira premissa quanto em sua conclusão, justamente essa suposta verdade.

Quanto ao significado dos atributos que conferimos a Deus, sabemos que uma qualidade tal como a inteligência tem significado somente a partir da

\footnotetext{
${ }^{40}$ HOLLEY, ob. cit. p. 88.

${ }^{41}$ Cf. Ibid. p. 84-88.

${ }^{42}$ HUME, David. Dialogues Concerning Natural Religion, D 2 § 3, p. 44.

${ }^{43}$ HUME, David. A Treatise of Human Nature. Ed. D. F. Norton \& M. J. Norton. Oxford: University Press, 2002, 1.3.3.
} 
nossa experiência da inteligência humana. Holley argumenta que se nos dirigirmos a algo muito remoto da inteligência humana, perdemos a referência e, sem ela, tornamo-nos impossibilitados de dizer algo de consistente sobre o assunto. Para ele, internamente à religião teísta está o ímpeto de nos depurarmos do antropomorfismo e, ao mesmo tempo, de arrastarmo-nos a ele. Nas palavras de Holley: “a análise de Hume sobre o monoteísmo localiza uma tensão entre o impulso de formar concepções antropomórficas e o anseio de elevar a divindade para além da imaginação humana" ${ }^{44}$ E este ansioso conflito resulta em uma flutuação contínua na formação de conceitos sobre o divino - o que justificaria o desacordo relativo à concepção antropomórfica do ser divino entre, de um lado, o teísta ortodoxo e o cético (que a rejeitam) e, de outro, o teísta experimental (que a abraça).

Convém lembrar que a participação de Demea nos Diálogos é bem menor do que a de Cleanthes e Philo. Hume não despende muitas páginas para tratar da prova a priori, pois a única prova que ele considera digna de investigação é a prova a posteriori. Nesse ponto, a pequena participação de Demea (que não deixa de ser importante) talvez possa ser justificada pelo fato de que Hume nunca considerou válido qualquer argumento ou raciocínio a priori quando estes são aplicados às questões de fato ou existência. Ele já havia excluído esse tipo de procedimento ao apresentar seu "método de estabelecer conclusões relativas às questões de fato" no Tratado e também em EHU. De qualquer modo, Hume sabia da importância que a prova a priori tinha no contexto das discussões filosóficas e teológicas do período. Ora, sendo Demea um representante e defensor do cristianismo ortodoxo rejeitado por Hume, e também daquilo que chamei de fideísmo místico, é natural que suas opiniões exerçam um papel bem menor do que as de Cleanthes e Philo. Dessa perspectiva, um outro papel de Demea seria, digamos assim, estrategicamente, o de levantar questões cruciais para serem discutidas pelos outros dois personagens, bem como o de colocar questões que dessem a oportunidade de os outros dois elaborarem suas próprias posições.

\section{Existência de Deus e Natureza Divina}

Conforme procurei mostrar, Demea não está isento de alguma espécie de misticismo. ${ }^{45}$ Entretanto, esse misticismo fideísta não se localiza propriamente no âmbito da defesa da existência de Deus. Toda a argumentação

\footnotetext{
${ }^{44}$ HOLLEY, ob. cit. p. 87.

${ }^{45}$ Mutatis mutandis, Hume já havia tocado nessa questão no final da seção 10 da EHU, intitulada Dos Milagres, quando, ao tentar desacreditar os milagres assevera que "o método de raciocínio aqui exposto agrada-me ainda mais quando penso que ele pode servir para confundir aqueles amigos perigosos ou inimigos disfarçados da religião cristã, que se propuseram a defendê-la pelos princípios da razão humana. Nossa mais sagrada religião está
} 
em termos fideístas ocorre no que tange à natureza divina. É nesse sentido que, a meu ver, o misticismo de Demea permanece restrito à sua concepção mais religiosa. Ele sugere estar alinhado aos "autênticos teístas", ou seja, àqueles que defendem que é preciso crer para compreender (como Anselmo, na esteira de Agostinho) ${ }^{46}$, e que sustentam que algumas verdades são acessíveis à razão, e outras não o são (como Agostinho, Anselmo e Tomás de Aquino). ${ }^{47}$ Portanto, para as verdades não acessíveis à razão, só a fé poderia nos convencer delas.

Pois bem, a natureza divina, de acordo com Demea, não é acessível à razão, apenas a sua existência. A existência de Deus não só pode como deve ser provada por um argumento da teologia racional. Isso mais uma vez reforça a tese segundo a qual, em relação à existência de Deus, Demea não adere a um fideísmo místico religioso, embora seja possível defender a necessidade de uma demonstração dedutiva para a existência Divina, e ainda assim defender um fideísmo místico quanto a essa questão. Para se ter fé na natureza divina é preciso acreditar que Deus existe. Contudo, acreditar que Deus existe independe de sua existência ser demonstrada por argumentos racionais. Mas é isso que Demea pensa e defende? Espero ter mostrado que não. A seguinte passagem pode ser oferecida como mais um abono à restrição do misticismo de Demea ao âmbito religioso:

Este mundo não é senão um ponto em comparação com o universo; esta vida, apenas um momento em comparação com a eternidade. Os fenômenos malignos presentes, por conseguinte, são retificados em outras regiões e em algum período futuro da existência. E os olhos dos homens, sendo então abertos para perspectivas mais amplas das coisas, veem a conexão integral das leis gerais e seguem, com veneração, a benevolência e retidão da divindade, através de todos os labirintos e meandros de sua providência. ${ }^{48}$

\footnotetext{
fundada na fé, não na razão, e um método seguro de pô-la em risco é submetê-la a uma prova que ela não está de modo algum preparada para enfrentar" (HUME, David. EHU 10 § 40, pp. 185-186). Essa passagem poderia sugerir que Hume está a esposar o fideísmo? Penso que não. Acredito que há boas razões para argumentar que essa não é sua posição. Porém, há que se levar em conta que, nos Diálogos, Philo aponta para uma espécie de fideísmo ao argumentar que a natureza divina só pode ser discernida pelos olhos da fé (HUME, David. Dialogues Concerning Natural Religion, D $10 \S 36$, p. 104). Sobre esse ponto: FERRAZ, Marília Côrtes de. O status do fideísmo na crítica de Hume à religião natural, 2016, p. 108.

${ }^{46}$ No capítulo I do Proslógio Anselmo afirma: “Não tento, ó Senhor, penetrar a tua profundidade: de maneira alguma a minha inteligência amolda-se a ela, mas desejo, ao menos, compreender a tua verdade, que o meu coração crê e ama. Com efeito, não busco compreender para crer, mas creio para compreender. Efetivamente creio, porque, se não cresse, não conseguiria compreender" (CANTUÁRIA, Anselmo de. Proslógio. São Paulo: Abril Cultural, Coleção “Os Pensadores", 1979, p. 101).

${ }^{47} \mathrm{Na}$ Súmula Contra os Gentios, por exemplo, Tomás de Aquino escreve um capítulo intitulado: "É justo que as verdades inacessíveis à razão sejam propostas aos homens como objetos de fé" (AQUINO, Tomás de. Súmula Contra os Gentios. Tradução de Luiz João Baraúna. São Paulo: Abril Cultural, Aquino, 1973, parte I cap. V, p. 67.

${ }^{48}$ HUME, David. Dialogues Concerning Natural Religion, D $10 \S 29$, p. 101.
} 
Note-se que nessa passagem Demea se compromete com a doutrina da vida pós-morte, algo que não pode ser propriamente sustentado por argumentos racionais (quer dizer, a razão não tem poderes para isso). Hume, na voz do amigo epicurista da seção 11 da EHU, já havia argumentado contra essa tese reduzindo-a a uma mera hipótese, aliás, das mais implausíveis e improváveis, ${ }^{49}$ e Cleanthes, logo na sequência dessa passagem, alega que tais argumentos estão fundados em suposições arbitrárias. A crença num estado vindouro é atacada também por outras vias. No ensaio Da imortalidade da alma Hume põe em dúvida as razões que temos para crer que a alma é imortal, e defende a mortalidade da alma. Ele pergunta:

por meio de quais argumentos ou analogias podemos provar um estado de existência que ninguém jamais viu e que não se assemelha a qualquer coisa que já foi vista? Quem depositará tamanha confiança numa pretensa filosofia para admitir, sob seu testemunho, a realidade de um lugar tão maravilhoso ${ }^{50}$

A posição de Demea a respeito da incompreensibilidade da natureza divina segue, pois, a tradição de autores como Anselmo, Tomás de Aquino, Descartes, Malebranche ${ }^{51}$ e mesmo Hobbes, para citar apenas alguns.

Tomás de Aquino, por exemplo, afirma que não podemos obter conhecimento da natureza de Deus de maneira completa e plena. Ele diz: "A razão não pode atingir uma forma simples de modo a lhe conhecer a quididade; pode, contudo, conhecer-lhe a existência". ${ }^{52}$ Ainda: "A inteligência humana é incapaz, pelas suas próprias forças, de apreender a substância ou a essência íntima de Deus. [...] E, todavia, os objetos sensíveis conduzem a nossa inteligência a um certo conhecimento de Deus, até ao ponto de conhecermos que Ele existe". ${ }^{53}$ Já Hobbes declara a respeito de todas as qualidades convencionais atribuídas a Deus que "todos os seus atributos constituem indícios de nossa inabilidade e falta de capacidade de conceber o que quer que seja acerca de sua natureza". ${ }^{54}$

${ }^{49}$ HUME, David. An Enquiry concerning Human Understanding, $11 \S 21$, p. 193.

${ }^{50}$ HUME, David (E): Of the immortality of the soul. Essays: moral, political, and literary. Edited by Eugene E. Miller. Indianapolis: Liberty-Classics, 1987, Essay 10, p. 598.

${ }^{51}$ Este último explicitamente citado nos Diálogos sobre a Religião Natural (D 2 § 2, pp. 43-44).

${ }^{52}$ AQUINO, Tomás de. Suma Teológica, parte I, questão XII, art. XII.

${ }^{53}$ AQUINO, Tomás de. Súmula Contra os Gentios, parte I cap. III, p. 65)

${ }^{54}$ HOBBES, Thomas. Os elementos da lei natural e política: tratado da natureza humana: tratado do corpo político, 2002, $1.11 \S 2$, p. 75 . Estou ciente de que há uma polêmica discussão em torno de se Hobbes era de fato um teísta ou um ateu. Mas, para não me desviar de meus propósitos, devo abster-me desse debate. Cito-o apenas como exemplo de alguém que, a despeito de sua real posição, fez declarações (ainda que, talvez, irônicas ou retóricas) que convergem com o teísmo tradicional. 


\section{Considerações Finais}

Demea já havia sido acusado de místico por Cleanthes, mas não aceitou esse epíteto, considerando-o uma alcunha tão aviltante e de tão perigosas consequências quanto a de antropomorfista. ${ }^{55}$ Ora, quais seriam essas perigosas consequências? De acordo com Demea, a partir da representação antropomórfica da Divindade como similar à mente e entendimento humanos, não haveria como compatibilizar a alma do homem, "um composto de várias faculdades, paixões, sentimentos e ideias", com a "perfeita imutabilidade e simplicidade que todos os autênticos teístas atribuem à Divindade". ${ }^{56}$ Qualquer analogia entre Deus e o homem sempre resultará em ideias inadequadas e numa depreciação dos atributos divinos. Por isso, a natureza divina jamais pode ser tomada como objeto de conhecimento, e qualquer tentativa de conhecê-la não significa apenas uma pretensão desmedida, mas também impiedade. No entanto, a discussão até aí está apenas começando. Estamos ainda na quarta parte das doze que compõem a obra. Na sequência, Cleanthes continuará a insistir em sua acusação ao declarar que a tese de Demea (da simplicidade e imutabilidade divinas) o autoriza a taxá-lo de rematado místico e, no fundo, um ateísta sem o saber. Para Cleanthes, admitir uma mente totalmente simples e imutável ${ }^{57}$ é conferir atributos que são absolutamente incompatíveis com a natureza intelectiva essencial da Divindade. De acordo com ele, uma mente integralmente simples e imutável não pode nem mesmo ser mente, pois não exibe pensamento, razão, tampouco vontade e qualquer sentimento. ${ }^{58}$ Demea não replica. É Philo quem entra em cena chamando a atenção de Cleanthes para as censuras que ele professa e para mais algumas inconveniências do antropomorfismo que ele adota - assunto que deixo para tratar em outro artigo.

\section{Referências}

AQUINO, Tomás de (2003). Suma Teológica, Vol. I, Parte I, Questão XII, Art. XII e XIII (Latim-Português). São Paulo: Loyola.

AQUINO, Tomás de (1973). Súmula Contra os Gentios. Tradução de Luiz João Baraúna. São Paulo: Abril Cultural.

BERKELEY, George (1973): Três diálogos entre Hilas e Filonous em oposição aos céticos $e$ ateus. $1^{\underline{a}}$ edição. Tradução de Antonio Sérgio. São Paulo: Abril S.A. Cultural e Industrial.

\footnotetext{
${ }_{55}^{5}$ HUME, David. Dialogues Concerning Natural Religion, D 4 §§ 1-2, p. 60-61.

${ }^{56}$ Ibid. D 4 § 2, p. 60-61.

${ }^{57}$ Cleanthes, como se pode perceber, abdica aqui de noções essenciais relativas às ideias que temos de Deus: a perfeita simplicidade e imutabilidade divinas.

${ }^{58}$ Ibid. D 4 §, p. 61.
} 
CANTUÁRIA, Anselmo de (1973). Proslógio. São Paulo: Abril Cultural, Coleção "Os Pensadores".

CÍCERO, Marco Túlio (2004). Da Natureza dos Deuses. Tradução de Pedro Braga Falcão. Lisboa: Nova Veja.

FERRAZ, Marília Côrtes de (2016). O status do fideísmo na crítica de Hume à religião natural. In: CONTE; FERRAZ e ZIMMERMANN. Ensaios sobre a filosofia de Hume. Florianópolis: NEL/UFSC. - (Coleção Rumos da Epistemologia; volume 16) - pp.105-118.

FERRÉ, Frederick e FERRÉ R. (1984). In Praise of Anthropomorphism. In: International Journal for Philosophy of Religion, Vol 16, $\mathrm{n}^{\circ}$ 3, pp. 203-212. Published by Springer. Stable URL: http://www.jstor.org/stable/40012658 . Accessed: 09/03/2010.

HOBBES, Thomas (2002). Os elementos da lei natural e política: tratado da natureza humana: tratado do corpo político. Tradução e notas: Fernando Dias Andrade. São Paulo: Ícone.

HOBBES, Thomas (2002). Os elementos da lei natural e política: tratado da natureza humana: tratado do corpo político. Tradução e notas: Fernando Dias Andrade. São Paulo: Ícone.

HOLLEY, David M. (2002). The Role of Anthropomorphism in Hume's Critique of Theism. In: International Journal for Philosophy of Religion, vol. 51, $\mathrm{n}^{\circ} 2$ (April, 2002), pp. 83-99. Published by Springer. Stable URL: http://www.jstor.org/stable/40020994 Accessed: 09/03/2010.

HUME, David. (EHU): An Enquiry concerning Human Understanding. Edited by Tom L. Beauchamp. Oxford: University Press, 1999.

HUME, David (T): A Treatise of Human Nature. Ed. D. F. Norton \& M. J. Norton. Oxford: University Press, 2002.

HUME, David (D): Dialogues Concerning Natural Religion and (NHR) The Natural History of Religion. Edited by J. C. A. Gaskin. Oxford: University Press, 1993.

HUME, David (E): Essays: moral, political, and literary. Edited by Eugene E. Miller. Indianapolis: Liberty-Classics, 1987.

PIKE, Nelson (1970). Hume on the argument from design. In: HUME, David. Dialogues Concerning Natural Religion. Edited and with commentary by Nelson Pike. New York: Bobbs-Merrill Company, pp. 127-238.

PITSON, Tony (2008). The Miseries of Life: Hume and the Problem of Evil. In: Hume Studies. Vol. 34, Number 1, April.

Endereço da Autora:

Rua Raposo Tavares, 1140 - Apto 11-C

86010-580 Londrina - PR

mariliacortes@hotmail.com 